\title{
ISOLATION OF 2, 5-DITHIA-3, 6-DIAZABICYCLO [2.2.1] HEPTANE AND GC-MS ANALYSIS OF SILYLATED EXTRACT FROM Tragia benthamii
}

\author{
Balogun O. S., ${ }^{1}$ Oladosu, I. A., ${ }^{2}$ and Zhiqiang Liu ${ }^{3}$ \\ ${ }^{1}$ Department of Chemistry, Obafemi Awolowo University, Ile-Ife, Osun-State, Nigeria. \\ ${ }^{2}$ Department of Chemistry, University of Ibadan, Ibadan, Nigeria. \\ ${ }^{3}$ Centre for Mass Spectrometry, Changchun Institute of Applied Chemistry, \\ Chinese Academy of Sciences, Changchun, China. \\ balogunolaoye@oauife.edu.ng; solomonoye@gmail.com; Tel: +2348034940850 \\ (Received: $15^{\text {th }}$ January, 2020; Accepted: $14^{\text {th }}$ May, 2020)
}

\section{ABSTRACT}

\begin{abstract}
Tragia benthamii is a medicinal plant of repute endemic in West Africa. However, despite the traditional uses of the plant its secondary metabolites are yet to be profiled. Thus, this study aimed at identifying the chemical constituents of T. benthamii. Air-dried samples $(600 \mathrm{~g})$ of the plant were extracted with aqueous ethanol $(95 \%)$ and thereafter, portions of the crude extract obtained were used separately for chromatographic purifications, GC-MS analysis and spectrophotometric quantitation of the secondary metabolites. The chromatographic purification of the extract afforded a pure compound elucidated as 2,5-dithia-3,6-diazabicyclo [2.2.1] heptane using spectroscopic techniques. Upon silylation and GC-MS analysis of the extract, derivatives of sugar (34.65\%), fatty acids $(24.11 \%)$ and phytol $(21.00 \%)$ were identified as principal constituents. Also, a total of 6.25 $\mathrm{mg}$ rutin/g, $5.18 \mathrm{mg}$ ginsenoside/g and $6.84 \mathrm{mg}$ glucose/g dry weight sample were obtained for flavonoids, saponins and carbohydrate, respectively from the spectrophotometric quantitation. These secondary metabolites are being reported for the first time from this plant.
\end{abstract}

Keywords: Tragia benthamii; secondary metabolites; quantitative analysis; silylation

\section{INTRODUCTION}

Tragia benthamii is a trailing herb occurring from Ivory Coast to west of Cameroon and extending widespread to Sudan, Zaire and Angola (Burkill, 1983). A leaf-mash of the plant is used for treatment of sore in Ghana and Nigeria. It is commonly employed as abortificient or to promote child delivery in Ivory Coast (Burkill, 1983). The plant is also recognized for its antimalarial potential, and listed among plants for treatment of fever in Zambia. The extracts of the $T$. benthamii and $T$. furialis have been shown to possess in vivo antimalarial activity at concentration higher than $50 \mathrm{mg} / \mathrm{kg}$ (Innocent $e t$ al., 2009, Oladosu et al., 2013). Other biological activities such as cytotoxicity, antioxidative stress and antibacterial activity have been reported for species like T. involucrata, T. spathulata and T. pungens (Palani et al., 2009, Dhara et al., 2002, Chatterjee et al., 1980). However, reports on chemical composition of tragia species are scanty. Panda $e t$ al., 2012 and Samy et al., 1998 reported the isolation of a number of compounds such as stigmasterol, quercetin, rutin, $3-(2,4-$ dimethoxyphenyl)-6,7-dimethoxy-2,3dihydrochromen-4-one, vinyl hexyl ether, shellsol, 2,4-dimethyl hexane, 2-methylnonane and 2,6dimethyl heptane from various solvent fractions of T. involucrata. To the best of our knowledge there is no documented research on isolation of pure compound from $T$. benthamii. Thus, we report herein the isolation and characterisation of a pure natural product, identification of derivatized constituents and quantitation of secondary metabolites from extract of T. benthamii.

\section{MATERIALS AND METHODS}

\section{Plant material}

The whole plant T. benthamii was collected from a farmland in Ibadan, Oyo State in August 2016. The plant was identified and authenticated by $\mathrm{Mr}$ M.O. Onadeji at Forestry Research Institute of Nigeria (FRIN) Ibadan, Oyo State. A voucher specimen (FHI 108456) was deposited at the FRIN herbarium.

\section{Extraction}

The air-dried and pulverised whole plant of $T$. benthamii $(600 \mathrm{~g})$ was exhaustively percolated with $95 \%$ aqueous ethanol with intermittent ultrasonication for $72 \mathrm{~h}$ at room temperature. 
Thereafter, the solvent was removed in vacuo to give the crude extract ( $32 \mathrm{~g})$. Portions of the crude extract obtained were used separately for chromatographic purifications, GC-MS analysis and spectrophotometric quantitation of carbohydrate, flavonoids and saponins.

\section{Purification of extract}

About $26 \mathrm{~g}$ of the crude were suspended in water and partitioned using $\mathrm{n}$-hexane and chloroform successively. The chloroform extract $(8 \mathrm{~g})$, was chromatographed on silica gel column and fractionated using gradient of hexane/chloroform and choloform/methanol to give 82 fractions which were pooled to 12 subfractions (C 1-12). The sub-fractions C-11 eluted by $\mathrm{CHCl}_{3}: \mathrm{MeOH}, 2: 3$ afforded an yellowish-white solid which was washed with isopropyl alcohol and re-crystallised in methanol to give compound $\mathbf{1}(6.5 \mathrm{mg})$.

IR: $v_{\max }\left(\mathrm{cm}^{-1}\right)$ with $\mathrm{KBr}: 2962(\mathrm{C}-\mathrm{H}), 1151(\mathrm{C}-\mathrm{N})$, $1604(\mathrm{~N}-\mathrm{H})$,

MS: 156.87

$\left[\mathrm{C}_{3} \mathrm{H}_{6} \mathrm{~N}_{2} \mathrm{~S}_{2}+\mathrm{Na}\right]^{+}$

${ }^{13} \mathrm{C}$ NMR (D $\left.\mathbf{O}, 50 \mathrm{MHz}\right): \delta \mathrm{c} 34.55\left(\mathrm{C}_{-1}\right)$ and $51.25\left(\mathrm{C}_{-2}\right)$.

${ }^{1} \mathbf{H}$ NMR (D $\left.\mathbf{2} \mathbf{O}, 200 \mathrm{MHz}\right): \delta \mathrm{H} 2.77(2 \mathrm{H}, \mathrm{m}) 3.84$ $(2 \mathrm{H}, \mathrm{m})$ and $3.22(\mathrm{~N}-\mathrm{H})$

\section{Silylation of extract}

Water-free pyridine $(50 \mu \mathrm{L})$ was used to dissolve $2.00 \mathrm{mg}$ of the plant extract and thereafter silylating agent, N,O-bis-(trimethylsilyl) trifluoroacetamide $(60 \mu \mathrm{L})$ containing $1 \%$ trimethylchlorosilane was added. The mixture was then heated at $80{ }^{\circ} \mathrm{C}$ for $20 \mathrm{~min}$ to give a silylated product. The product was dissolved in chloroform and analysed on GC-MS

\section{GC-MS Analysis}

The silylated extract was analysed on TSQ 8000 Evo GC (Thermo Scientific) system with a Mass Selective Detector equipped with a HP-5MS (5\% Phenyl methyl siloxane) capillary column (length $30 \mathrm{~m}$, inner diameter, $0.25 \mathrm{~mm}$ and film thickness $0.25 \mu \mathrm{m}$ ). One microliter of the sample was injected. The GC oven initial temperature was 40 ${ }^{\circ} \mathrm{C}$ for $1 \mathrm{~min}$ and was taken through two successive ramps. Ramp 1 was maintained at $15.0^{\circ} \mathrm{C} / \mathrm{min}$ to a final temperature of $180.0^{\circ} \mathrm{C}$, with $1 \mathrm{~min}$ hold time while ramp 2 was set at $5.0^{\circ} \mathrm{C} / \mathrm{min}$ to final temperature of $300.0{ }^{\circ} \mathrm{C}$, with hold time of 8 mins. Helium gas, at flow rate of $1.00 \mathrm{~mL} / \mathrm{min}$ was used as carrier gas and $1.0 \mu \mathrm{L}$ of the sample was injected in the splitless mode. The splitless flow and splitless time were was $33.3 \mathrm{~mL} / \mathrm{min}$ and $1.0 \mathrm{~min}$, respectively. The GC was coupled to MS transfer line heater maintained at $250{ }^{\circ} \mathrm{C}$ with EI (positive) ionisation mode. The mass range was 30-600 amu at scan time of $0.2 \mathrm{~s}$.

Qualitative identification of different constituents was based on comparisons of the relative retention indices and mass spectra with those of the Wiley and NIST library of the GC/MS through the use of probability merge search software and the NIST MS spectra search program. The relative amount (\% composition) of individual component of the oil was expressed as percentages of their peak areas relative to the total peak area (Balogun and Liu, 2020).

\section{Quantitative determination of some secondary metabolites Total carbohydrate}

Total carbohydrate of the extracts was determined using phenol-sulphuric acid method. This involved a standard calibration graph prepared by preparing varied concentrations from a standard glucose stock solution $(0.2 \mathrm{mg} / \mathrm{mL})$ as working standard into series of test tubes. About $1 \mathrm{~mL}$ of phenol $(5 \%)$ and $5 \mathrm{~mL}$ of conc. sulphuric acid were successively added to each working standard and shaken. The test tubes were placed in water bath at $25-30{ }^{\circ} \mathrm{C}$ for $20 \mathrm{~min}$ and the absorbance readings were determined at $490 \mathrm{~nm}$. Absorbance readings were plotted against concentrations to obtain a standard graph. The plant extract $(50 \mathrm{mg})$ was hydrolysed by adding $5 \mathrm{~mL}$ of $2.5 \mathrm{M} \mathrm{HCl}$ and kept in boiling water for $3 \mathrm{~h}$. The excess acid was neutralised with $\mathrm{Na}_{2} \mathrm{CO}_{3}$ (until the effervescence stopped). The resulting test solution was centrifuged and $0.2 \mathrm{~mL}$ was subjected to the same treatment as the working standards. Concentration was calculated using the equation of the standard graph $y=0.088 x+0.0299\left(R^{2}=\right.$ 0.997 ) and expressed in $\mathrm{mg}$ glucose/g dry weight. Water was used in place of plant extract for the blank.

\section{Total flavonoid}

A method described by Ghasemzadeh et al. 2010, 
was adopted. The aqueous solution of the plant extract $(2 \mathrm{mg} / \mathrm{mL}), 5 \%(\mathrm{w} / \mathrm{w}) \mathrm{NaNO}_{2}(0.7 \mathrm{~mL})$ and $30 \%(\mathrm{v} / \mathrm{v})$ ethanol $(10 \mathrm{~mL})$ was mixed for 5 minutes, and then $10 \%(\mathrm{w} / \mathrm{w}) \mathrm{AlCl}_{3}(0.7 \mathrm{~mL})$ was added and mixed together. Six minutes later, $1 \mathrm{M}$ $\mathrm{NaOH}(5 \mathrm{~mL})$ was added. The solution was then diluted to $25 \mathrm{~mL}$ with $30 \%$ (v/v) aqueous ethanol. After standing for 10 minutes, the absorbance of the solution was measured at $430 \mathrm{~nm}$. A standard curve was plotted using rutin as a standard flavonoid. Different concentrations of rutin were prepared in $80 \%$ ethanol and their absorbance values were determined at $430 \mathrm{~nm}$ on a spectrophotometer. The results were expressed in $\mathrm{mg}$ rutin/g dry weight by comparison with the rutin standard graph $\mathrm{y}=0.0012 \mathrm{x}+.0057\left(\mathrm{R}^{2}=\right.$ 0.9957).

\section{Total saponin}

The test extract $1 \mathrm{mg} / \mathrm{mL}$ was mixed with $0.2 \mathrm{~mL}$ $5 \%$ vanillin in acetic acid and $0.8 \mathrm{~mL}$ perchloric acid. The reaction mixture was heated at $60{ }^{\circ} \mathrm{C}$ in water bath for 15 minutes and cooled. The mixture was properly shaken after addition of $5 \mathrm{~mL}$ glacial acetic acid and absorbance was determined at 550 nm. A standard curve was plotted using ginsenoside Rb1 as a standard saponin. Different concentrations of ginsenoside Rb1 were prepared in water and subjected to the same treatment as test sample. The results were expressed in $\mathrm{mg}$ ginsenoside/g dry weight by comparison with the ginsenoside standard graph $\mathrm{y}=0.0035 \mathrm{x}-0.0127$ $\left(R^{2}=0.9985\right)$.

\section{RESULTS}

The phytochemical screening of the crude extract indicated the presence of tannins, saponins, alkaloids, cardiac glycoside and carbohydrate. Chromatographic purification of the extract afforded 2,5-dithia-3,6-diazabicyclo[2.2.1] heptane. The GC-MS analysis indicated the presence of sixteen compounds, predominantly derivatives of sugar $(34.65 \%)$, fatty acids $(24.11 \%)$ and phytol $(21.00 \%)$ (Table 1$)$. The results of quantitative determination of flavonoids, saponins and carbohydrates content of $T$. benthamii are shown in Table 2. A total of $6.25 \mathrm{mg}$ rutin/g, $5.18 \mathrm{mg}$ ginsenoside/g and $6.84 \mathrm{mg}$ glucose/g dry weight sample were obtained for flavonoids, saponins and carbohydrate, respectively.

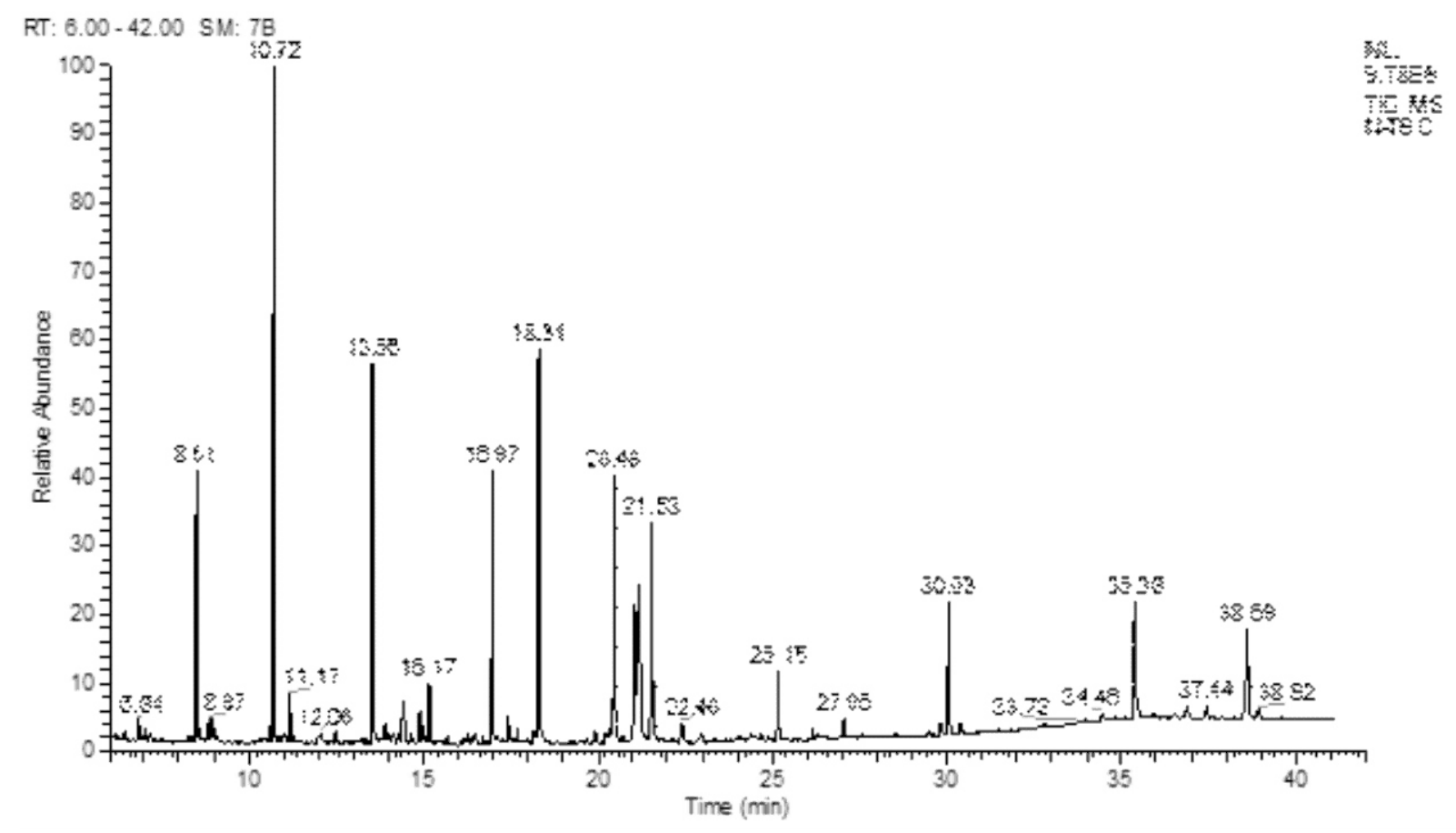

Fig.1 GC chromatogram of silylated extract of T. benthamii 
Table 1: Chemical constituents of silylated extract of T. benthamii

\begin{tabular}{lcc}
\hline Compound & RT(min) & \% Composition \\
\hline Glycerol & 8.51 & 6.73 \\
Erythritol & 10.73 & 15.21 \\
2,6-Bis(tert-butyl)phenol & 11.16 & 2.54 \\
D-(+)-Arabitol & 13.56 & 11.71 \\
3-Deoxyhexitol & 15.17 & 1.32 \\
D-Mannitol & 16.97 & 6.41 \\
Undecanoic acid, 2,8-dimethyl-, methyl ester & 17.44 & 1.04 \\
Palmitic acid & 18.31 & 12.41 \\
Phytol & 20.48 & 21.00 \\
9,12-Octadecadienoic acid (Z,Z)- & 21.06 & 1.57 \\
a-Linolenic acid & 21.18 & 2.51 \\
Stearic acid & 21.54 & 6.58 \\
3,5-di-tert-Butyl-4-hydroxyanisole & 25.15 & 2.98 \\
1-Monopalmitin & 27.05 & 0.53 \\
D-(+)-Trehalose, octakis(trimethylsilyl) ether & 30.03 & 4.52 \\
1-(3-Methylbutyl)-2,3,5-trimethylbenzene & 35.37 & 2.94 \\
\hline Total & & $\mathbf{1 0 0}$ \\
\hline
\end{tabular}

RT- Retention time

Table 2: Quantitative determination of some secondary metabolites in T. benthamii extract

\begin{tabular}{ccc}
\hline mg rutin/g sample \pm SD & mg ginsenoside/g sample \pm SD & mg glucose/g sample \pm SD \\
\hline $6.25 \pm 0.25$ & $5.18 \pm 0.38$ & $6.84 \pm 0.08$ \\
\hline
\end{tabular}

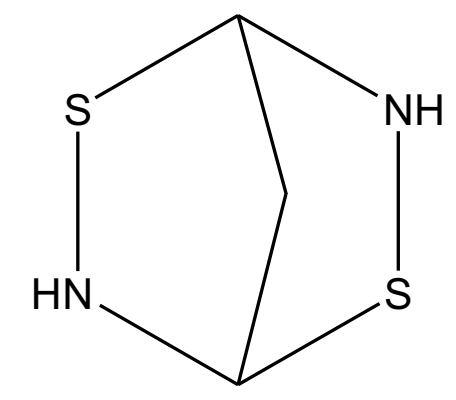

Compound 1: 2,5-dithia-3,6-diazabicyclo[2.2.1] heptane

\section{DISCUSSION}

This result of the phytochemical screening agreed with what was obtained by Mothana et al., 2010 which qualitatively identified a number secondary metabolite including flavonoids, saponin, alkaloids, carbohydrate, tannins and anthraquinone from $T$. benthamii. Compound 1 was obtained as a yellowish-white powder from the medium polar fraction of the plant. It has a melting point of $258-259{ }^{\circ} \mathrm{C}$ and showed diagnostic absorption bands for C-H, C-N and N$\mathrm{H}$ at 2962, 1151 and $1604 \mathrm{~cm}^{-1}$ respectively in the
IR spectrum. The ESI-MS showed the molecular ion peak at $\mathrm{m} / \mathrm{z}$ of $156.87[\mathrm{M}+\mathrm{Na}]^{+}$which suggested a molecular formula of $\mathrm{C}_{3} \mathrm{H}_{6} \mathrm{~N}_{2} \mathrm{~S}_{2}$.

The ${ }^{13} \mathrm{C}$ NMR spectrum revealed two carbon signals at $\delta_{C} 51.3$ and 34.55 which were resolved by attached proton test experiment into a methine and a methylene, respectively. The chemical shift of the methine carbon was typical of carbon linked to a heteroatom ( $\mathrm{N}$ and/or $\mathrm{S})$. The ${ }^{1} \mathrm{H}$ NMR spectrum showed two proton 
environments and the chemical shifts were characteristic of protons in neighbourhood of an electronegative atom. The spectrum showed a two-proton multiplet at $2.77 \mathrm{ppm}$ for the bridgehead protons while protons at position 1 and 4 which coupled with the bridgehead methylene resonated as multiplet at $3.84 \mathrm{ppm}$, also the N-H proton had $\delta 3.22$. The HSQC spectrum indicated correlation of carbon atoms at $\delta 51.25$ and $\delta 34.55$ with protons at $\delta 3.84$ and $\delta 2.77$ respectively. Based on the spectroscopic features, the compounds was elucidated as 2,5-dithia-3,6diazabicyclo [2.2.1] heptane. However, NOESY experiment might be needed to establish the stereochemistry of the compound. This is a first record of isolation and characterisation of this natural product from Tragia benthamii.

Fatty acids such as palmitic (12.41\%), stearic $(2.51 \%)$ and linolenic $(1.57 \%)$ acid detected by GC-MS in T. benthamii extract (Table 1) have been reported as the predominant fatty acid in unsilylated extract of Tragia plukenetii, with palmitic acid being the principal fatty acid in both plants $(21.28 \%$ in $T$. plukenetii). High content of dietary palmitic acid had been linked to reduction in serum cholesterol (Sundram, 1994), selective destruction of human leukemic cell (Harada, 2002) and anti-inflamatory activity. A diterpenoid, phytol was of the highest concentration $(21.00 \%)$ in the extract (Fig.1). Phytol-rich extract have been reported to exhibit antimicrobial (Fitsiou et al., 2007; Radulovic et al., 2011) alleopathic (Razavi and Nejad-Ebrahimi, 2010) and insecticidal activities (Mohamed et al., 1992). From the spectrophotometric analysis, flavonoids and saponins were estimated as $6.25 \mathrm{mg}$ rutin/g and $5.18 \mathrm{mg}$ ginsenoside/g respectively (Table 2). Though isolation of saponins is yet to be reported in Tragia specie, Oladosu et al., 2013, had reported detection of saponin in the phytochemical screening of $T$. benthamii extract but, found flavonoid absent. Flavonoids such as quercetin and rutin have been isolated from T. involucrate (Panda et al., 2012).

\section{CONCLUSION}

The presence of secondary metabolites such as fatty acids, flavonoids and saponins in T. benthamii is indicative of the pharmacological potentials of the plant. These metabolites were present in an appreciable quantity and therefore could be isolated and screened for biological activities. The compound, 2,5-dithia-3,6-diazabicyclo[ 2.2.1] heptane was obtained for the first time from the plant.

\section{ACKNOWLEDGEMENT}

The authors appreciated the support provided by Chinese Academy of Sciences through the award of PIFI CAS for visiting Scholar, 2017. The GCMS analysis of the silylated extract was carried out at Centre for Mass Spectrometry, Changchun Institute of Applied Chemistry, Changchun, China.

\section{REFERENCES}

Balogun, O. S., Ajayi, Ajayi, O. S. and Adeleke, A. J. (2017). Hexahydrofarnesyl AcetoneRich Extractives from Hildegardia barteri. Journal of Herbs, Spices \& Medicinal Plants, DOI: 10.1080/10496475.2017.1350614

Balogun, O.S and Liu, Z. (2020). Chemical constituents and lipase inhibitory activities of solvent fractions of Anthocleista vogelii stem bark. J. Chem Soc. Nigeria 45 (1) $165-170$.

Burkill, H.M. 1983. The Useful Plants of West Tropical Africa. 5, 6-7.

Chatterjee, A. and Sukul, N. C. (1980). Nematicidal action of three wild plants. Nematologica 26Nematologica 26 (4), 500502.

Dhara A. K., Pal, S. and Chaudhuri, A. K. (2002). Psychopharmacological studies on Tragia involucrata root extract. Phytotherapy Research 16, 326-330.

Filipowicz, N., M. Kaminski, M. and J. Kurlenda, J.. 2003. Antibacterial and antifungal activity of juniper berry oil and its selected components. Phytother. Res. 17:227-231.

Fitsiou, L., Tzakou, O., Hancianu, O. and Poiata, A. (2007). Volatile constituents and antimicrobial activity of Tilia tomentosa Moench and Tilia cordata Miller oils. J. Essent. Oil Res.19(2), 183-185.

Ghasemzadeh, A., Hawa, Z., Jaafar, E. and Rahmat, A. (2010). Antioxidant activities, total phenolics and flavonoids content in two varieties of Malaysia young ginger (Zingiber officinale Roscoe). Molecules 15, 4324-4333. 
Harada, H., Yamashita, U., Kurihara, H., Fukushi, E., Kawabata, J. and Kamei, Y. (2002). Antitumor activity of palmitic acid found as a selective cytotoxic substance in a marine red alga. Anticancer Res. 22(5), 2587-2590.

Innocent, E., Mainen, J., Moshi, A., Pax J. Masimba, P. J., Mbwambo, Z. H., Kapingu, M. C., Kamuhabwa, A. (2009). Screening of traditionally used plants for in vivo antimalarial activity in mice. African Journal of Traditional, Complementary and Alternative Medicine 6 (2), 163-167.

Mohamed, M. A., Quisenberry, S. S. and Moellenbeck, D. J. (1992). 6,10,14Trimethylpentadecan-2-one: A Bermuda grass phagostimulant to fall armyworm (Lepidoptera: Noctuidae). J. Chem. Ecol. 18(4), 673-682.

Mothana, R.A ., Abdo, S. A., Hasson, S., Faisal, M. N., Alaghbari, S. A. and Lindequist, U. (2010). Antimicrobial, antioxidant and cytotoxic activities and phytochemical screening of some Yemeni medicinal plants. Advance Access Publication 7 (3), 323-330

Oladosu, I. A., Balogun, S. O., Ademowo, G. O. (2013). Phytochemical screening, antimalarial and histopathological studies of Allophylus africanus and Tragia benthamii. Chinese Journal of Natural Medicne. 11 (4), 371-376.

Palani, S., Kumar, S., Gokulan, R. and Rajalingam, D. (2009). Drug Invention Today 1 (1), 5560.

Panda, D., Dash, S. K. and Dash, G. K. (2012). Phytochemical Examination and antimicrobial activity of various solvent extracts and the selected isolated compounds from roots of Tragia involucrata Linn. International Journal of Pharmaceutical Sciences and Drug Research 4 (1), 44-48.

Panda, D., Dash, Dash, S. K. and Dashand Dash, G. K. 2012. Phytochemical Examination and antimicrobial activity of various solvent extracts and the selected isolated compounds from roots of Tragia involucrata Linn. International Journal of Pharmaceutical Sciences and Drug Research 4.1: 44-48

Radulovic, N., Dekic, M.,.M., Stojanovic-Radic, Z. O and Palic, R. (2011). Chemical composition and antimicrobial activity of the essential oils of Geranium columbinum L. and G. lucidum L. (Geraniaceae). Turk. J. Chem. 35(3), 499-512.

Razavi, S. M. and Nejad-Ebrahimi, S. (2010). Phytochemical analysis and allelopathic activity of essential oils of Ecballium elaterium A. Richard growing in Iran. Nat. Prod. Res. 24(18), 1704-1709

Samy, P. R., Ignacimuthu, S., and Sen, A. (1998). Screening of thirty four Indian medicinal plants for antibacterial properties. Journal of Ethnopharmacology 62, 173-182.

Smith, K. M., Jesudoss, L. L., Ganthi, A. S., Subramanian, M. P. S. (2015). GC-MS Analysis of the Ethanol Extract of Tragia plukenetii R. Journal of Pharmacognosy and Phytochemistry 4(3), 253-256

Sundram, K., Hayes, K. C. and Siru, O. H. (1994). Dietary palmitic acid results in lower serum cholesterol than does a lauricmyristic acid combination in normolipemic humans. Am. J. Clin. Nutr. 59 (4), 841-846. 